\title{
Does Conventional Endodontic Treatment Impact Oral Health-related Quality of Life? A Systematic Review
}

\author{
(1) Leonardo S. ANTUNES, (1) Claudia R. SOUZA, (1) Alessandro G. SALLES, (D) Cinthya C. GOMES, \\ (D) Livia A. ANTUNES
}

Please cite this article as: Antunes LS, Souza CR, Salles AG, Gomes CC Antunes LA. Does Conventional Endodontic Treatment Impact Oral Health-related Quality of Life? A Systematic Review. Eur Endod J 2018; 3: 2-8

From the Department of the Specific Formation (L.S.A., C.C.G., L.A.A. \leonardoantunes@id.uff. br), Fluminense Federal University School of Dentistry, Nova Friburgo, RJ, Brazil; School of Dentistry (C.R.S.), Fluminense Federal University, Niteroi, RJ, Brazil; Program of Postgraduate A.G.S.), Fluminense Federal University School of Dentistry, Niteroi, RJ, Brazil

Received 20 March 2017, revision requested 6 June 2017, last revision received 12 September 2017, accepted 21 September 2017

Published online: 2 November 2017 DOI 10.5152/eej.2017.17008

This work is licensed under a Creative Commons Attribution-NonCommercial 4.0 International License.

\begin{abstract}
Could conventional endodontic treatment have an impact on oral health-related quality of life? There are still unresolved questions regarding this theme. In order to answer them, a systematic review on the available literature was undertaken to identify the methodological quality of and the risk of bias in all relevant studies. A broad search for articles was conducted, and only articles published before May 2016 were considered for review. The following portals were used: Pubmed, VHL (Medline, SciELO, Lilacs and BBO), Cochrane Library, and Web of Science. The keywords used for the search were 'quality of life' and 'root canal treatment.' Furthermore, we included MeSH synonyms, related terms and free terms. Articles written in any language were included according to the PICOS approach (population, intervention, comparison, outcome and study design). After application of these eligibility criteria, selected articles were qualified by assessing their methodological quality and potential risk of bias. The initial search identified 302 references. After excluding duplicated abstracts and analysing the titles and abstracts, 6 were selected. One study was added via manual search of the reference lists. From these, 2 were eligible for quality assessment and were classified as being of high methodological quality and as having low risk of bias. Based on these studies, it can be concluded that conventional endodontic treatment improves oral health-related quality of life. However, these results should be interpreted with caution, due to the lack of important methodological details in the included studies. Additional investigations are warranted to provide more evidence on this subject.
\end{abstract}

Keywords: Conventional endodontic treatment, oral health, quality of life, satisfaction, systematic review, therapeutics

\section{HIGHLIGHTS}

- To date, evidence of the effectiveness of endodontic treatment and criteria of success have mainly been considered in terms of clinical outcome.

- There is a lack of information of treatment outcomes from patients' perspectives evaluating the impact of endodontic treatment on Oral health related quality of life.

- Endodontic treatment improves the oral health related quality of life.

- The evaluation of this theme is useful for understanding patients' perspectives of outcomes from endodontic care

\section{INTRODUCTION}

There is an increasing interest in the effect that dental treatments have on quality of life. The root canal treatment is an important part of this because endodontic problems are a common occurrence in dental practice and are a key reason patients seek dental care (1). Oral health-related quality of life (OHRQoL) is a multidimensional construct that reflects, among other things, the comfort of the individual when feeding and during sleep, social interactions, selfesteem and satisfaction with their oral health (2). The scientific dental community has made efforts to develop adequate instruments to evaluate the extent to which certain oral conditions occur within affected populations, and the effectiveness of health services in this area. Instruments measuring OHRQoL have become essential for measuring the population's perception of the impact of oral 
disorders on well-being, as well as for the evaluation of a treatment regimen's impact on the affected population's quality of life (3).

Recently, patient reports of OHRQoL have begun to complement the limited professional evaluation, which is based only on clinical parameters. This allows for the development of treatment plans that are more suitable to the preferences and needs of the patients (4). Therefore, it is important to evaluate the quality of evidence provided by articles that propose to detect changes in OHRQoL after oral interventions. This evaluation must be done on a multi-item scale with instruments validated for quality of life, instead of using batteries of questions that differ in length, content and administration (5).

At the same time, there are still unresolved questions regarding the impact of endodontic treatment on OHRQoL. Some authors have detected that patients undergoing endodontic treatment have a clear and positive message, as the natural dentition is saved whenever possible, and observed that endodontic treatment benefits quality of life $(4,6)$. However, other studies have shown that the presence of persistent pain adversely impacts the patient's perceived OHRQoL (7). It is assumed that unsuccessful treatment, iatrogenic procedures, and even later tooth loss can also adversely impact OHRQoL. Therefore, a detailed scientific analysis is needed. Within this context, this study aims to systematically review the available literature to assess the methodological quality of and risk of bias in all relevant studies in order to report the findings focused on the following question: Does conventional endodontic treatment impact OHRQoL?

\section{MATERIALS AND METHODS}

This systematic review was registered in the PROSPERO database, registry number CRD42015029574, and followed the PRISMA Statements (8).

\section{Eligibility criteria}

Inclusion criteria outline articles written in any language according to the population, intervention, comparison, outcome and study design (PICOS) as follow:

Population (P): healthy humans;

Intervention (I): conventional endodontic treatment;

Comparison (C): OHRQoL evaluation before conventional endodontic treatment;

Outcome (O): change in OHRQoL after conventional endodontic treatment;

Study design (S): interventional longitudinal study.

The following exclusion criteria were applied: articles not using validated OHRQoL instruments, articles that did not evaluate OHRQoL before and after conventional endodontic treatment, case reports, cross sectional studies, review articles, articles evaluating endodontic surgeries, book chapters, theses, guidelines, and articles with quality assessments evaluated at high risk of bias.

\section{Search strategy}

A broad search for articles was conducted, and only articles published before May 2016 were considered for review, without language restriction. The following databases were

TABLE 1. Search strategy

PubMed \#1 (Quality of life [MeSH Terms]) OR Quality of life [Title/Abstract]) OR Oral Health Impact Profile [Title/Abstract]) OR QoL [Title/Abstract])

OR OHIP [Title/Abstract]) OR OHRQoL [Title/Abstract])

\#2 (Dental Pulp Diseases [MeSH Terms]) OR Dental Pulp Diseases [Title/Abstract]) OR Periapical Abscess [MeSH Terms]) OR Periapical Abscess [Title/Abstract]) OR Periapical Periodontitis [MeSH Terms]) OR Periapical Periodontitis [Title/Abstract]) OR root canal treatment [Title/Abstract]) OR endodontic treatment [Title/Abstract]) OR Teeth, Endodontically Treated [Title/ Abstract]) OR apical periodontitis [Title/Abstract])

$\# 1$ and \#2

Scopus \#1 (TITLE-ABS-KEY (quality of life) OR TITLE-ABS-KEY (oral health impact profile) OR TITLE-ABS-KEY (qol) OR TITLE-ABS-KEY (ohip) OR TITLE-ABS-KEY (ohrqol))

\#2 (TITLE-ABS-KEY (dental pulp diseases) OR TITLE-ABS-KEY (periapical abscess) OR TITLE-ABS-KEY (periapical periodontitis) OR TITLEABS-KEY (root canal treatment) OR TITLE-ABS-KEY (endodontic treatment) OR TITLE-ABS-KEY (teeth, endodontically treated) OR TITLEABS-KEY (apical periodontitis))

$\# 1$ and \#2

WOS \#1 TOPIC: (Quality of Life) OR TOPIC: (Oral Health Impact Profile) OR TOPIC: (QoL) OR TOPIC: (OHIP) OR TOPIC: (OHRQoL)

\#2 TOPIC: (Dental Pulp Diseases) OR TOPIC: (Periapical Abscess) OR TOPIC: (Periapical Periodontitis) OR TOPIC: (root canal treatment) OR TOPIC: (endodontic treatment) OR TOPIC: (Teeth, Endodontically Treated) OR TOPIC: (apical periodontitis)

$\# 1$ and \#2 diseases)) OR (tw: (periapical abscess)) OR (tw: (periapical periodontitis)) OR (tw: (root canal treatment)) OR (tw: (endodontic treatment)) OR (tw: (teeth, endodontically treated)) OR (tw: (apical periodontitis)) 


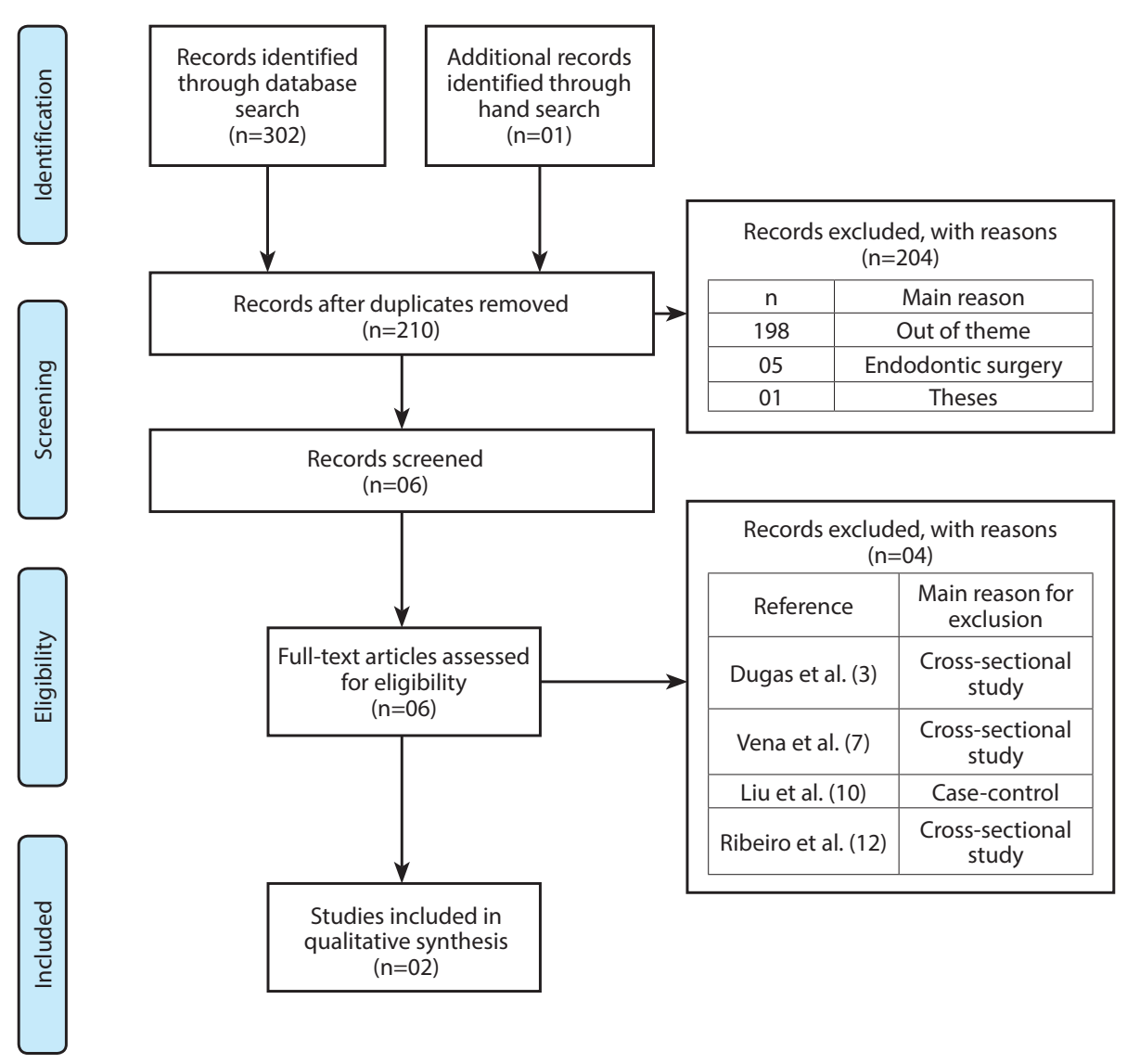

Figure 1. Prisma flow diagram showing the literature search protocol, articles screening and exclusion criteria

used: Pubmed, Lilacs, Scopus and Web of Science. The grey literature was consulted through OpenGrey (http://www. opengrey.eu). Researchers were contacted to identify additional studies. The MeSH (Medical Subject Headings) terms (www.nlm.nih.gov/mesh/meshhome.html) used in the search were 'quality of life' and 'root canal therapy.' Furthermore, we included MeSH synonyms, related terms and free terms (Table 1). The Boolean operators 'AND' and 'OR' were applied to combine the keywords. The searches were complemented by screening the references of the selected articles to find any related study that did not appear in the database search.

\section{Studies selection}

Initially, two of the authors (AGS and LSA) selected the studies by title and abstract according to the previously described eligibility criteria. To evaluate the authors' selections, $10 \%$ of the publications were randomly selected and had their classification compared; a Kappa statistic of 0.97 was determined based on agreement between authors. Only articles that matched the inclusion criteria were accepted. Articles appearing in more than one database were considered only once (Figure 1). Subsequently, the full texts of the potentially eligible studies were accessed and the inclusion criteria were applied again. Any disagreement was discussed and solved by consensus or discussion with a third review author (LAA). After inclusion of the abstracts that fulfilled the selection criteria and verification of their eligibility by reading the complete articles, the studies were submitted to verify the quality assessment and risk of bias.

\section{Quality assessment and risk of bias}

The methodological quality assessment and risk of bias of the selected studies were independently evaluated by two authors (AGS and LSA). Differences between authors were solved by consensus. Assessments of quality and of risk of bias of the included studies were carried out according to previous studies $(5,9)$, with a checklist that included 12 items (Table 2). Each quality criterion was assessed as present (yes, score of 1 point) and absent or undetermined (no, score of 0 point). Based on their scores, the studies were classified into three categories: i) high methodological quality: presenting 8 or more criteria and low risk of bias; ii) moderate methodological quality: presenting 4-7 criteria and moderate risk of bias; iii) low methodological quality: presenting 3 or fewer of the evaluated criteria and high risk of bias. Considering the methodological quality and risk of bias (low, moderate and high), the studies were also classified as having high, moderate and low evidence accordingly. Only studies with high and moderate evidence were used in this systematic review.

\section{Data collection}

The data from the included papers were compiled. The data was organised according to: author, year of publication, country, aim of study, instrument of OHRQoL, sample size, 
TABLE 2. Methodological scoring protocol based on quality assessment and risk of bias for selected studies (Total=2)

Quality assessment*

Article

Criteria evaluated

Hamasha and

Hatiwsh (2013)

Liu et al. (2014)

Study design

A- Description of eligibility criteria: inclusion/exclusion criteria: Were the characteristics of the patients included in the study clearly described?

B- Description of the sample: Was the sample size determined and/or were those subjects representative of the entire population from which they were recruited?

C- Description of the groups allocation in the study: Were the study subjects randomly divided into different intervention groups?

Intervention

D- Were the interventions of interest clearly described?

E-Were the follow-up and period of recruitment described?

Statistical methods

F- Description of statistical methods used: Were the statistical tests used to assess the main outcomes appropriate?

Instrument to analyse the quality of life (Description of instrument's psychometrics properties) G- Description of instrument's applicability in the tested population: Was the instrument applied appropriately for the population group?

$\mathrm{H}$ - Description of instrument's reliability: Were internal consistencies or previous information about instrument validation present in the paper?

I- Description of test-retest reliability: Was there a questionnaire test-retest analyses?

J- Description of the instrument's responsiveness: Was there any analysis or previous information about the instrument capacity to detect changes in QoL?

Results

K- Did a large number of patients return for follow up after clinical intervention (above 80\%)?

L- Have the characteristics of patients lost at follow up been described?

Total score

Methodological quality

Risk of bias

Level of evidence

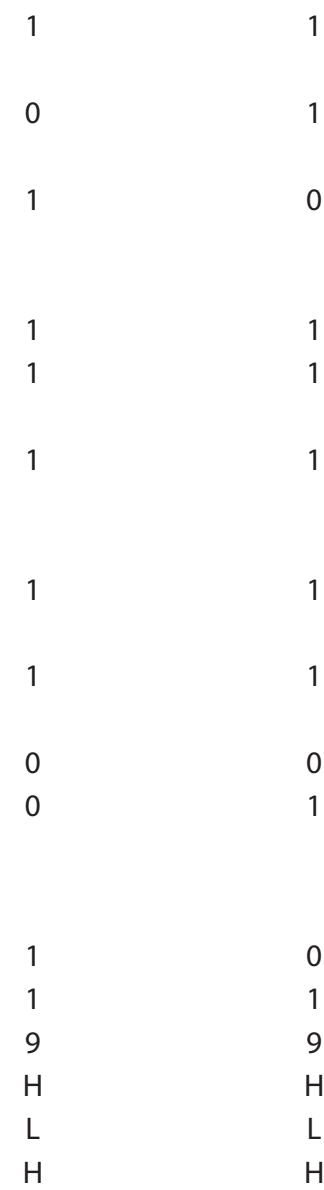

${ }^{*}$ Quality assessment criteria were adapted from Antunes et al.(15)

H: High, M: Moderate, L: Low

mean age, time of follow up, rate of response, mean score on OHRQoL instrument before and after treatment, professional training, tooth type, procedure type, instruments, period between visits, irrigation solution, canal filling, restoration after treatment and outcome.

\section{RESULTS}

The initial search identified 302 references in the electronic databases: 147 from Scopus, 80 from Web of Science, 49 from PubMed and 26 from Lilacs. After excluding the duplicates, and analysing the titles and abstracts, five articles were selected $(3,4,7,10,11)$. One study was added via manual search of the reference lists, totalising six articles. After full access and detailed analysis based on the exclusion and inclusion criteria, four of the six articles were excluded and two were eligible for quality assessment (12). The reasons for exclusion were as follows: three studies were cross-sectional studies $(3,7,12)$ and one study was a case-control study (10). An overview of the literature search is shown in Figure 1.
The two eligible studies $(4,11)$ were deemed to be of high methodological quality and to have a low risk of bias (Table 2) as having high methodological quality and low risk of bias. These two studies were included in the qualitative synthesis.

Data extraction (qualitative synthesis) from the selected articles is described in Tables 3 and 4. The extracted data revealed the use of the OHRQoL instruments to evaluate changes after conventional endodontic treatment. The questionnaires applied were the Oral Health Impact Profile-OHIP-14 and OHIP17. Both studies reported the time of follow-up.

\section{DISCUSSION}

Evidence-based dentistry provides a careful approach to oral health by harvesting systematic analysis of scientific evidence to answer a clinical question (13). To develop appropriate treatment plans, dentists should match patients' needs and preferences with the best treatment according to the available scientific evidence. Therefore, it is of utmost importance to as- 
TABLE 3. Methodological scoring protocol based on quality assessment and risk of bias for selected studies (Total=2)

\begin{tabular}{|c|c|c|c|c|c|c|c|c|c|c|}
\hline \multirow[b]{2}{*}{$\begin{array}{l}\text { References } \\
\text { (year) }\end{array}$} & \multirow[b]{2}{*}{ Country } & \multirow[b]{2}{*}{ Aim } & \multirow[b]{2}{*}{$\begin{array}{c}\text { OHRQoL } \\
\text { Instrument } \\
\text { Applied } \\
\text { (interviewer) }\end{array}$} & \multirow[b]{2}{*}{$\begin{array}{l}\text { Sample age } \\
\text { (mean } \pm S D)\end{array}$} & \multirow[b]{2}{*}{ sample } & \multirow[b]{2}{*}{$\begin{array}{l}\text { Time of } \\
\text { follow } \\
\text { up }\end{array}$} & \multirow[b]{2}{*}{$\begin{array}{l}\text { Final } \\
\text { Sample/ } \\
\text { return for } \\
\text { follow up }\end{array}$} & \multicolumn{2}{|c|}{$\begin{array}{l}\text { Mean of overall score } \\
\text { of OHRQoL instrument }\end{array}$} & \multirow[b]{2}{*}{ Outcome } \\
\hline & & & & & & & & $\begin{array}{c}\text { Before } \\
\text { endodontic } \\
\text { intervention }\end{array}$ & $\begin{array}{c}\text { After } \\
\text { endodontic } \\
\text { intervention }\end{array}$ & \\
\hline Liu et al. (2014) & China & $\begin{array}{l}\text { To assess } \\
\text { QoL after } \\
\text { conventional } \\
\text { endodontic } \\
\text { treatment }\end{array}$ & OHIP-14 & $\begin{array}{l}\text { Adults } 18 \\
\text { years and } \\
\text { older } \\
(45.6 \pm 3.2)\end{array}$ & 279 & $\begin{array}{l}1 \text { month and } \\
6 \text { months }\end{array}$ & $213(76.3 \%)$ & $15.1 \pm 10.2$ & $\begin{array}{l}1 \text { month } \\
\text { later: } \\
8.9 \pm 8.6 \\
6 \text { month } \\
\text { later: } \\
7.8 \pm 8.0\end{array}$ & $\begin{array}{l}\text { All } 7 \text { domains of } \\
\text { the OHIP-14 } \\
\text { presented } \\
\text { significant difference } \\
\text { in the domain } \\
\text { scores over time. }\end{array}$ \\
\hline $\begin{array}{l}\text { Hamasha and } \\
\text { Hatiwsh (2013) }\end{array}$ & Jordan & $\begin{array}{c}\text { To assess } \\
\text { the impact } \\
\text { of primary } \\
\text { root canal } \\
\text { treatment on } \\
\text { the perceived } \\
\text { QoL }\end{array}$ & OHIP-17 & $\begin{array}{c}\text { Adults } \\
\text { aged 18-60 } \\
\text { years }\end{array}$ & 340 & 2 weeks & 302 (88.8\%) & 8.44 & $4.03 \pm 0.12$ & $\begin{array}{l}\text { More than } 90 \% \\
\text { postoperative } \\
\text { improvement was } \\
\text { noted for pain, eating } \\
\text { and difficulty } \\
\text { relaxing. }\end{array}$ \\
\hline
\end{tabular}

QoL: Quality of life, OHRQoL: Oral-health-related quality of life, OHIP: Oral health impact scale

TABLE 4. Methodological scoring protocol based on quality assessment and risk of bias for selected studies (Total=2)

\begin{tabular}{|c|c|c|c|c|c|c|c|c|c|c|}
\hline $\begin{array}{l}\text { References } \\
\text { (year) }\end{array}$ & Professional & $\begin{array}{l}\text { Type of } \\
\text { tooth }\end{array}$ & $\begin{array}{c}\text { Type of } \\
\text { procedure }\end{array}$ & Instruments & Visits & $\begin{array}{c}\text { Period } \\
\text { between } \\
\text { visits }\end{array}$ & $\begin{array}{l}\text { Irrigation } \\
\text { solution }\end{array}$ & $\begin{array}{l}\text { Canal } \\
\text { filling }\end{array}$ & $\begin{array}{c}\text { Restoration } \\
\text { after } \\
\text { treatment }\end{array}$ & Outcome \\
\hline $\begin{array}{l}\text { Liu et al. } \\
\text { (2014) }\end{array}$ & WD & $\begin{array}{l}\text { Anterior, } \\
\text { premolar } \\
\text { and molar }\end{array}$ & $\begin{array}{l}\text { Treatment and } \\
\text { retreatment }\end{array}$ & WD & WD & WD & WD & WD & WD & $\begin{array}{l}\text { Changes in } \mathrm{OHQ} \text { oL } \\
\text { are associated with } \\
\text { changes in oral } \\
\text { health (both clinical } \\
\text { and subjective } \\
\text { changes). }\end{array}$ \\
\hline $\begin{array}{l}\text { Hamasha } \\
\text { and } \\
\text { Hatiwsh } \\
(2013)\end{array}$ & $\begin{array}{l}\text { Undergraduate } \\
\text { students; } \\
\text { Graduate } \\
\text { students; } \\
\text { Endodontic } \\
\text { specialists. }\end{array}$ & $\begin{array}{l}\text { Incisors, } \\
\text { canine, } \\
\text { premolar } \\
\text { and } \\
\text { molar }\end{array}$ & $\begin{array}{c}\text { Primary and } \\
\text { nonsurgical } \\
\text { instruments, } \\
\text { Conventional } \\
\text { hand files. }\end{array}$ & $\begin{array}{c}\text { Rotary } \\
\text { NiTi } \\
\text { Multiple } \\
\text { dental } \\
\text { visits using } \\
\text { nonsetting } \\
\text { calcium } \\
\text { hydroxide as } \\
\text { dressin materia } \\
\text { between visits }\end{array}$ & $\begin{array}{l}\text { Single-visit } \\
\text { treatments } \\
\\
\text { s } \\
\text { ial } \\
\text { ts. }\end{array}$ & $\begin{array}{l}\text { t One } \\
\text { s week }\end{array}$ & $\begin{array}{c}\text { Sodium } \\
\text { hypochlorite }\end{array}$ & $\begin{array}{l}\text { Gutta-percha } \\
\text { using the }\end{array}$ & $\begin{array}{l}\text { Filled using } \\
\text { light -cured } \\
\text { glass-ionomer } \\
\text { cement followed } \\
\text { by permanent } \\
\text { restorations. }\end{array}$ & $\begin{array}{l}\text { No significant } \\
\text { difference in } \\
\text { improvement } \\
\text { between patients } \\
\text { treated by specialists, } \\
\text { graduate students } \\
\text { or undergraduate } \\
\text { students. } \\
\text {-The quality of life } \\
\text { improvement scores } \\
\text { were significantly } \\
\text { higher for teeth with } \\
\text { vital pulps compared } \\
\text { to teeth with necrotic } \\
\text { pulps }\end{array}$ \\
\hline
\end{tabular}

WD: Without data, NiTi: Nickel titanium

sess the quality of life reported by articles that detect changes in OHRQoL after oral treatment (5).

In endodontics, it is very important to evaluate the outcome of a treatment through research on OHRQoL. In the present study, a systematic review was undertaken to detect if conventional endodontic treatment improves the patient's OHRQoL. To evaluate endodontic outcomes, we assessed studies designed to measure OHRQoL before and after treatment. Two studies met the criteria followed in this systematic review, and were considered to be of a high methodological quality and to have a low risk of bias. Results revealed an improvement in OHRQoL after conventional endodontic treatment, but we emphasise the careful evaluation of these studies because, although they were classified as low risk of bias, this does not mean that there is no risk. Some flaws in the application of OHRQoL instruments were observed. Measuring instruments should be guided by properties that make them reliable and valid. The test-retest reliability of a survey is determined by interviewing candidates at different moments in time, including the beginning and the end of the study. The instrument ability to detect changes in quality of life, or responsiveness, is another property that is mainly used in clinical trials to test the changes during treatment $(14,15)$. However, both Hamasha \& Hatiwsh (11) and Liu et al. (4) did not undergo test-retest, resulting in instability of 
the study. Only Liu et al. (4) tested the responsiveness of the survey - this instrument has the ability to detect changes in quality of life between the two times of application (before and after treatment). Furthermore, some criteria suggested by the CONSORT Statement (Consolidated Standards of Reporting Trials) checklist to ensure the absence of biased results were not followed (16).

The lack of data standardisation of the two accessed studies made it impossible to compare the results in a meta-analysis. Since methods of conventional endodontic treatment were not standardised in the studies assessed in this systematic review and since each study applied different clinical parameters and their clinicians had different levels of experience, it was not possible to compare the results in a meta-analysis.

With regards to OHRQoL, a number of parameters are mentioned below that may contribute to the improvement of future methodologies to achieve the best evidence in order to bring positive changes in the quality of life of individuals after conventional endodontic treatment.

The selected studies carried out follow-up appointments after endodontic therapy. Liu et al. (4) conducted observation for 6 months. However, in the study by Hamasha \& Hatiwsh (11), the follow-up was carried out after only two weeks. The time of follow-up in the study of Hamasha \& Hatiwsh (11) may have influenced the final result of the research. Follow-ups are indispensable. According to Travassos et al. (17), a period of two to five years is necessary to observe complete repair. Thus, some authors believe that a follow up postoperative periapical radiograph is essential every six months for two years, which will show either normal healing processes or tissue changes suggestive of failure (18). Therefore, the authors recommend the application of an OHRQoL instrument at the time of initial clinical and radiographic examination and at follow-ups during a period of up to two years to examine if the treatment has successfully improved the patient's oral health and quality of life without restriction. Vena et al. (7) demonstrated that some patients experienced persistent pain during the follow-up period, which lasted up to five years after the primary root canal therapy. This lasting pain may adversely impact quality of life. Several studies have shown that pain ceased for patients after endodontic therapy and they were able to lead a healthier and better quality life $(1,3,5,10)$. The impact of conventional endodontic treatment on quality of life in Hamasha \& Hatiwsh's (11) study was quite significant; over $90 \%$ of subjects reported improvement in quality of life after the root canal treatment. In this study, an alternative short version of the Oral Health Impact Profile (OHIP) was used. The original 49 items where narrowed to 17 items related to endodontic disease (3). These results are similar to the research of Liu et al. (4), where the Oral Health Impact Profile-short form (OHIP-14) was used in the context of conventional endodontic treatment. These models were used to recognise seven conceptual dimensions of impact, namely functional limitation, physical pain, psychological discomfort, physical disability, psychological disability, social disability and social disadvantage (19). Both studies showed that the highest score was on the physical pain subscale.
Systematic reviews and meta-analyses are increasingly important tools used for scientific evidence in health practices. They are particularly important for reviewing controversial therapeutic areas (8). These studies help to clarify and synthesise the evidence available in the literature and may help clinicians and researchers in their daily work. Although conventional endodontic treatment seems to improve oral health-related quality of life, further research should be carried out to improve the power of evidence and to permit the development of appropriate treatment plans in order to match the patient's needs and preferences with the best treatment according to the available scientific evidence. In addition, future analysis on the impact of surgical endodontic treatment as well as conventional endodontic retreatment procedures on OHRQoL is warranted.

\section{CONCLUSION}

Based on results of this systematic review, it can be concluded that conventional endodontic treatment improves the oral health related quality of life. However, more studies are warranted with improved methodological procedures and follow up for longer time intervals.

\section{Disclosures}

Acknowledgements: The authors thank Sarah Vinski for English editing assistance.

Conflict of interest: No conflict of interest was declared by the authors.

Peer-review: Externally peer-reviewed.

Financial Disclosure: The authors declared that this study has received no financial support.

Authorship contributions: Concept - L.S.A., L.A.A.; Design - L.S.A., C.R.S., A.G.S., C.C.G., L.A.A.; Supervision - L.S.A., L.A.A.; Resources - L.S.A., A.G.S., L.A.A.; Materials - C.R.S., A.G.S., C.C.G.; Data collection \&/or processing - C.R.S., A.G.S., C.C.G.; Analysis and/or interpretation - C.R.S., A.G.S., C.C.G.; Literature search L.S.A., A.G.S., L.A.A.; Writing - L.S.A., C.R.S., A.G.S., C.C.G., L.A.A.; Critical Review - L.S.A., C.R.S., A.G.S., C.C.G., L.A.A.

\section{REFERENCES}

1. Liu P, Mcgrath C, Cheung G. What are the key endodontic factors associated with oral health-related quality of life? Int Endod J 2014; 47(3):23845.

2. Dugas NN, Lawrence HP, Teplitsky P, Friedman S. Quality of Life and Satisfaction Outcomes of Endodontic Treatment. J Endod 2002; 28(12):81927.

3. Liu P, Endo MDS, Mcgrath C. Improvement in Oral Health - related Quality of Life after Endodontic Treatment: A Prospective Longitudinal Study. J Endod 2014; 40(6):805-10.

4. Antunes LAA, Andrade MRTC, Leão ATT, Maia LC, Luiz RR. Systematic review: change in the quality of life of children and adolescents younger than 14 years old after oral health interventions: a systematic review. Pediatr Dent 2013; 35(1):37-42.

5. Gatten DL, Riedy CA, Hong SK, Johnson JD, Cohenca N. Quality of life of endodontically treated versus implant treated patients: A universitybased qualitative research study. J Endod 2011; 37(7):903-9.

6. Vena DA, Collie D, Wu H, Gibbs JL, Broder HL, Curro FA, et al. Prevalence of Persistent Pain 3 to 5 Years Post Primary Root Canal Therapy and Its Impact on Oral Health - Related Quality of Life : PEARL Network Findings. J Endod 2014; 40(12):1917-21.

7. Stewart LA, Clarke M, Rovers M, Riley RD, Simmonds M, Steward G, et al. Preferred Reporting Items for Systematic Review and Meta-Analyses of individual participant data: the PRISMA-IPD Statement. JAMA 2015; 313(16):1657-65. 
8. Martins C, Buczynski AK, Maia LC, Siqueira WL, Castro GFB de A. Salivary proteins as a biomarker for dental caries-a systematic review. J Dent 2013; 41(1):2-8.

9. Liu P, McGrath C, Cheung GSP. Quality of life and psychological well-being among endodontic patients: A case-control study. Aust Dent 2012; 57(4):493-7.

10. Hamasha AA, Hatiwsh A. Quality of life and satisfaction of patients after nonsurgical primary root canal treatment provided by undergraduate students, graduate students and endodontic specialists. Int Endod J 2013; 46(12):1131-9.

11. Arrais Ribeiro IL, Veloso HHP, Valença AMG, Brasil Júnior O LNE. Evaluation of quality of life and level of user satisfaction of network of specialized care with the endodontic treatment in the municipality of João Pessoa, Paraíba, Brazil, 2009. Rev Bras Odontol Cent 2012; 21:55763.

12. Sischo L, Broder HL. Oral Health-related Quality of Life: What, Why, How, and Future Implications. J Dent Res 2011; 90(11):1264-70.

13. Schulz KF, Altman DG, Moher D. CONSORT 2010 statement: updated guidelines for reporting parallel group randomized trials. Ann Intern Med 2010; 152(11):726-32.

14. Travassos RMC, Caldas A de FJ, de Albuquerque DS. Cohort study of endodontic therapy success. Braz Dent J 2003; 14(2):109-13.

15. Slade GD, Spencer AJ. Social impact of oral conditions among older adults. Aust Dent J 1994; 39:358-64. 